\title{
Democracia y Justicia Social en México: entre la retórica y la realidad inaplazable
}

\author{
Armando Alfonzo Jiménez* y Fortino Delgado Carrillo \\ * Comisión Nacional de Derechos Humanos
}

\section{Introducción. La realidad nacional}

Hace más de 170 años comenzó un proceso -que aun no concluye- por consolidar un proyecto de nación que refleja anhelos y pesares. Que reconoce las capacidades y limitaciones de su gente, la desproporción que existe de la distribución de la riqueza, la influencia positiva y negativa de otras naciones. Dicho proyecto que se encuentra plasmado en síntesis paradójica entre lo ideal y lo real.

Es por eso que el siglo XIX representa una etapa cruenta y difícil para el desarrollo del país. Crisis ideológica e institucional se manifestaron como síntoma de una enfermedad que tuvo como desenlace final el movimiento social armado de 1910.

La Constitución de 1917 -fruto de las corrientes sociales de la épocamarcó el inicio de la estabilidad institucional y se ganó el orgulloso título de ser la primera declaración de derechos sociales.

Sin embargo, la realidad no sólo ha rebasado al dispositivo constitucional; ha ido en contra de su espíritu. Consecuencia de ello son las 400 reformas de la cual ha sido objeto, con lo que la idealidad nacional se ha visto seriamente condicionada por la realidad nacional.

El anhelo de "dar más a los que menos tienen", en pocos casos deja de ser un elemento más de la retórica que de la práctica social y gubernamental. Muestra de ello son las cifras oficiales sobre la pobreza en México, categoría que agrupa a más de la mitad de la población.

Pero, ¿cuál es el papel que desempeña el Estado para afrontar tales desigualdades?

Las líneas que se deslizan en el presente ensayo - que muestran nuestra obsesión por la historia- es ante todo un intento de traducir pensamientos dispersos, y ejercemos nuestro derecho a ello y a la libertad de pensamiento, con la convicción de que ésta, no muere en las discusiones académicas, sino que curiosamente es el lugar donde nace. 


\section{Las comillas del desarrollo}

En nuestros días, cuando el concepto de democracia transita en el vertiginoso y sórdido vaivén de las ideas, unas veces con el característico olor de la herejía por sus innovaciones, y otras, con la pretendida inamovilidad que produce la ortodoxia, se suele cavilar sobre los conceptos que asocia- dos a ella conducen el desarrollo nacional. En un país como el nuestro que con frecuencia da tumbos en su desarrollo socio-político, no puede inhibirse -ni mucho menos despreciarse- el papel que la democracia ha jugado en la vida de la sociedad nacional: sus avances y retrocesos, agravios y desagravios; todo en conjunto; inclusive, aquellos títulos decorosos que la política de la "modernidad" le ha signado en la actualidad, y que expone y denuncia una compleja cadena de necesidades, aspiraciones, angustias y molestias sociales latentes y manifiestas.

El contexto social del México de hoy desnuda sin decoros los atavismos de los sueños en que nuestra democracia circula en el discurso: los efectos de la pobreza y la extrema pobreza, la ausencia de programas permanentes de desarrollo social, la corrupción del aparato burocrático, los usos y abusos de nuestro sistema presidencial, las formas y estilos trastocados del arribo al poder. Son todos ellos, entre muchos otros, las manifestaciones de la democracia, de una realidad que da pasos hacia atrás sobre el espejismo de estarlos dando hacia adelante.

Las reformas de Estado que han pretendido acelerar el desarrollo del país, paradójicamente caen en el anquilosamiento merced a la inamovilidad del Estado y que redunda en su expresión más hiriente que es la pobreza.

A partir del Congreso Constituyente de 1916-1917 se han buscado mecanismos para alcanzar la justicia social. La justicia social es tesis fundamental de nuestra Ley Suprema y el actuar diario del Gobierno de la República y de la Sociedad Civil, mismos que deben estar encaminados al logro de dicho ideal.

Por ello, la injerencia del Estado en la población debe medirse potencialmente por las alternativas reales que cada mexicano tiene para mejorar su nivel de vida; a un Estado como el nuestro no debe jactarlo el hecho de ayudar a las clases más desprotegidas, porque esta noción de combate frontal contra la pobreza tácticamente, la reconoce e incrementa y, sobre todo, la institucionaliza. Si los programas contra la pobreza son permanentes, es porque la pobreza es más que un problema temporal.

La radiografía socio-económica de nuestro pueblo no es halagadora. Tan sólo en el Distrito Federal, y de acuerdo con cifras oficiales, "el 75\% de los 8.2 millones de capitalinos percibe ingresos de entre uno y tres salarios mínimos; más del 60\% de las familias depende de subsidios; cerca de cinco millones están desamparados asistencialmente; dos millones no cuentan con 
agua, drenaje y pavimentación; 500,000 están desempleados; 228,000 personas mayores de quince años no saben leer ni escribir; 125,000 viviendas se encuentran en pésimas condiciones de habitabilidad; 50,000 carecen de energía eléctrica, y seis de cada 100 personas viven con condiciones de pobreza extrema”.( Consejo Consultivo, 1990: 20) y sin embargo, se supone que el Distrito Federal respecto de los estados de la República Mexicana tiene avance considerable.

En términos generales, y pese al combate contra la pobreza, en 1987 alrededor de 41 millones de mexicanos (que representaban casi la mitad del país) eran pobres. Y de ellos, 17 millones de mexicanos se encontraban en condiciones de pobreza extrema; 30 millones se ubicaban en los estratos medios; y una minoría: 9.1 millones formaban parte de la capa más alta de la sociedad. En 1990, de un total de 23.5 millones de mexicanos que formaban la población económicamente activa, el 7.2\% no recibía ingresos; el 19.3\%, recibía menos de un salario mínimo; el 36.7\%, de uno a dos salarios mínimos; el $15.1 \%$, más de dos salarios mínimos, pero menos de 3.5\%; el 9.8\%, de tres a cinco salarios mínimos, y el 7.6\%, mas de cinco salarios mínimos. (Consejo Consultivo, 1990: 22)

En los últimos años, además de acrecentarse la población -ya somos casi 100 millones- los niveles de vida se han deteriorado, por lo que la filas de los pobres se han engrosado y en cálculos estimativos ascienden a 47 millones de mexicanos.

Creemos que el punto nodal de la pobreza en nuestro país está dado por las distancias que separan al gobierno de la sociedad, y que este distanciamiento a su vez provoca una ruptura casi natural en su comprensión y entendimiento mutuo. En ese tenor, el gobierno inhibe e incluso desprecia a la sociedad cuando le corresponde decidir, y la sociedad por su parte paga esta inllibición y desprecio deslegitimando la imagen y actos del gobierno, pero sobre todo con franca abulia en casi todas las decisiones de Estado que le involucran.

En México, la mayoría de los problemas endémicos de la sociedad son atribuibles el Estado. Por legitimidad o por costumbre -preguntaríamos-, quién se ha convertido históricamente en el conductor de los impulsos esenciales del desarrollo social. De ahí que, como curioso acto de vergüenza, asuma con frecuencia su responsabilidad y su intervención determine fundamentalmente el avance o retroceso de casi todos los renglones de la vida social.

Así, en una sociedad que gira y, metafóricamente, da vuelcos en tomo a las decisiones de gobierno, el Estado se convierte en su motor, su impulso y, casi, su alma. 


\section{El lado visible de la democracia}

Los hilos conductores de nuestra democracia nacional parten fundamentalmente del sistema político mexicano. Su concepción, madurez y proceso de legitimación, ha propiciado un aumento, disminución o, fatalmente, el anquilosa- miento de la democracia. El temperamento de la política nacional ha incorporado a la democracia en el columpio del tiempo, donde: la parte más alta de la más baja dista sólo una inercia incapaz de sostenerse, y el aferramiento al poder casi absoluto ha engendrado una democracia condicionada, relativa y extraordinariamente contradictoria.

La experiencia del pasado explica nuestro autoritarismo político, pero no justifica las vicisitudes del presente. El hecho de que la sociedad no puede retrotraerse en el tiempo, no sólo indica una condición natural, sino políticamente una razón de Estado que obliga a proponer una vida pública capaz de actualizarse, al comprender que el poder de hoy no es el mismo al poder que ejercía el cacique colonial o el caudillo revolucionario.

Nuestra sociedad ha cambiado de fondo y las propuestas que ofrece el Estado, tanto en el ejercicio público como en l oportunidades de participación social, no pueden seguir siendo las mismas de antaño. En rigor, hay que desgarrar las ataduras que ligan al pasado, porque un poder que vive del pasado, termina por morir también en el pasado.

La inquietud social por hacer efectivo un sistema democrático cada día es mayor. Respeto, tolerancia, conocimiento de nuestra realidad y mejoramiento de nuestras leyes, son elementos indispensables para conseguir que la democracia -tal y como la afirma el artículo $3^{\circ}$ de la Constitución General de la República- sea "una forma de vida". Otro factor importante es el papel que desarrolla el Partido Revolucionario Institucional. Su inamovilidad, su edad, su legitimación, los relevos en sus cuadros directivos, su pluralidad y hasta el modo y estilo de gastar el lenguaje oficial; todo ello junto, es parte esencial de nuestra democracia.

El partido de la revolución institucionalizada ha entrado ya a una etapa irreversible, donde los desatinos de hoy ya no se desdibujan en el tiempo como antes, sino se agudizan, quedan latentes y afectan de fondo a todo el sistema político nacional. Sin lugar a dudas, el primer ejercicio obligado del PRI es un proceso de introspección autocrítica que permita renovar sus viejas y caducas prácticas de poder que en 66 años de poder ininterrumpido se ha negado a modificar sustancialmente. El ejercicio autocrítico, más que minar las bases organizacionales, debe ser una obligación estratégica interna que le 
permita a esa organización diseñar mecanismos homeostáticos y no esperar la opinión extraoficial. Con ello, sin auto crítica permanente, esa organización incuba su propio aniquilamiento.

La estructura del partido gobernante parece inamovible. El gobernar por si y para sí, lejos de fortalecerlo, lo ha debilitado. Sin otras organizaciones dentro del poder que lo movilicen y lo obliguen a ejercer la creatividad, el PRI ha caído en su propia trampa. En la medida en que el PRI se convierta en un partido político más, estará dando pasos agigantados a su democratización y legitimación ante la sociedad.

Otro factor determinante que ha desfigurado una y otra vez la democracia, y que al igual que las anteriores involucra al partido mayoritario, son los procesos electorales.

Y es que en verdad pocas cosas en la historia política de México producen tanta fatalidad como el "fantasma" de las elecciones. La sociedad civil, con razón, se muestra renuente a concurrir a las urnas para ejercer su derecho constitucional de voto; en ocasiones por la escasa credibilidad política, y otras por la carencia de espíritu cívico. Esto debilita enormemente a la democracia.

Resulta curioso revisar el ejercicio del poder nacional en 66 años de existencia del PRI y de cómo ha pretendido compartir este poder con la oposición: el PRI ha ganado todas las elecciones para Presidente de la República, ha perdido muy pocas gubernaturas de estados -una de ellas otorgada por interinato-, ha dejado sólo unas cuantas curules en el Senado y espacios minoritarios en la Cámara Baja.

En los últimos tiempos el partido se ha agitado interna- mente. De su crisis surge una oposición propia: la corriente crítica o Democracia 2000 son un ejemplo. En ello, los grupos políticos se han enfrentado entre si; ha habido disidencias, revueltas, expulsiones y perdida de identidad partidista. Las causas sobran y se sintetizan en una simple dicotomía: viejas prácticas de corrupción de partido y por- que la demanda supera la oferta de espacios de poder.

Por otra parte, es conveniente apuntar que un sector de ese partido político se ha dado cuenta de la necesidad de legitimar al mismo, sin buscar el poder no por el poder mismo.

\section{Hacia una reforma de Estado}

El ritmo vertiginoso en que se mueven actualmente las sociedades modernas son el resultado de una constante y apasionada búsqueda por encontrar mejores condiciones de vida social, económica y política. La reforma de los Estados es intensa, las sociedades conscientes del acomodo del mundo. 
Las Reformas de Estado en México son escasas. Los cambios de fondo que el país registra en su historia pueden identificarse con cierta facilidad: 1810 representa el primer intento de Nación para nuestro país, y es un despertar violento y angustioso luego de tres siglos de conquista. Del régimen colonial a la Independencia hay un salto diametral. Aquí nace México propiamente.

A la mitad del siglo XIX proviene otra erupción nacional. La Reforma del Estado es profunda, intensa y por momentos contradictoriamente apoteósica y frustrante. La reforma liberal es la más encarnada al ser nacional, es pulcra y paralelamente avanzada. El país sube el columpio del tiempo y la relatividad de los hechos confunde: la generación liberal incuba la carta de 57 y de frente las facciones liberal y conservadoras disputan la supremacía política del país, la Nación se convierte en un foro de discusión y más que ello, en una arena de lucha. El arribo del grupo liberal al poder origina las Leyes de Reforma y la Guerra de los Tres Años. El triunfo liberal -que también es un triunfo de razón y legalidad-inconforma a los conservadores y atrae como consecuencia la Intervención Francesa y el Imperio de Maximiliano. Así, de 1856 y 1867, México naufraga en un mar de incomprensión y tragedia, por lo que desde entonces palabras como Juárez o República se mitifican y son evocaciones solemnes de Historia. Otra Reforma de Estado había concluido.

Lo de 1910 es otro viraje, la vuelta a la Reforma propiamente dicha, la No Reelección y El Sufragio Efectivo fueron dos respuestas para una multitud de preguntas. La Constitución del 17 las consagra y va más allá: pretendiendo proteger a dos sectores marginales, vejados y humillados por el gobierno del General Díaz: obreros y campesinos. Formalmente representó un ideal que busca el Estado de justicia social.

En 1929 Plutarco Elías Calles funda el Partido Nacional Revolucionario (PNR), recogiendo los intereses de los caudillos revolucionarios, quienes desde la muerte de Madero venían disputándose el poder. Fue, como es de sobra conocido, una fórmula bien pensada para institucionalizar la Revolución, con lo que se inició la estabilidad política de nuestro país. Terminaron con ello los asesinatos y las emboscadas en la irracional lucha por el poder. De esta forma, la fundación del PNR, sus cambios de 1938 y 1946, constituyen el pilar del más reciente sistema político mexicano. La Reforma de Estado del 29 también fue clara.

Contamos hasta aquí cuatro etapas de reforma, cuatro manifestaciones de México distintas y distantes, cuatro recuerdos del pasado vistos con nostalgia y emoción, cuatro intentos de nación cuyo punto de partida inició hace casi 186 años. Mas ¿qué ocurre entre una etapa y otra? 
Múltiples cambios -nos contestamos-, contrastes; convergencias y divergencias en el tiempo, sentidos y contrasentidos, pero todo bajo pautas establecidas. Se antoja fácil repasar la Historia de México, si todo fuera como transcribirla; de 1810 a 1996 son 18 décadas que muestran 75 años de guerra civil espaciada; cuatro mutilaciones del territorio nacional; 5 guerras con potencias extranjeras; 12 constituciones y 97 cambios de Poder Ejecutivo.

Hoy, el Gobierno Federal parece reencausar la Reforma de Estado de 1988 y, de su pasado inmediato ala actualidad, existen realidades diferentes. La orientación es sumar otra forma a las anteriores. Las palabras cambio y modernidad son dos propuestas que se funden en la realidad y la utopía, y son paradójicamente parte del discurso oficial y realidad social. Son de acuerdo a ello, punta de lanza política y genuinas aspiraciones sociales; son pues, la unidad de la diversidad.

Tras la toma de posesión de Salinas de Gortari en diciembre de 1988, se planteó de fondo un nuevo proyecto nacional. La promesa fue -y sigue siendo la de la actual administración- un México distinto. Un gobierno para la mayoría en el que en el centro de la escena estaba -y sigue estando- el pueblo.

Pero los hechos suscitados en 1994 parecen haber puesto al país en otro viraje: el levantamiento de los zapatistas, los asesinatos políticos, el inicio una nueva crisis financiera, todos factores que han contribuido para asistir a un momento de cambios con nuevos actores y con nuevas posibilidades de consolidar un proyecto de Nación, aunque las demandas populares sigan siendo las mismas.

Hoy, las reformas de fondo son más que necesarias. La sociedad lo advierte y por momentos lo vive. Pero sobre todo la Reforma de Estado que debe gestarse bajo el actual régimen tiene que basarse en la constitución de un Estado con rostro humano, ya que sin ello ningún avance, poco o muy significativo, trascenderá.

A partir de hace algunos años el gobierno había enderezado dos puntales para el rezago social, lacerante y vergonzoso, que haya su diáfana expresión en la categoría miseria. El Pacto para la Estabilidad y el Crecimiento Económico (PECE) y el Programa Nacional de Solidaridad (Pronasol), fueron dos instrumentos de política económica que el Estado mexicano empleó para el combate a la pobreza. El PECE y el Pronasol fueron dos estrategias que aparentemente combinaban sensibilidad política y estrategia económica a fin de obtener crecimiento y el desarrollo social sostenible.

El Estado de hoy ha intentado reformas, sobre todo en los ámbitos económicos y políticos, que aunque parecen limitados vale la pena recordar. 


\section{Los nudos del pasado. El fenómeno presidencial}

México es un claro producto de su historia. En la profunda contraposición de órdenes obsesivamente violados o super- puestos, que nos conducen invariablemente al mismo punto de partida. Justo ahí donde comenzamos a escribir la historia moderna de nuestra patria.

En ese tenor, México es una constante búsqueda condenado en un constante encuentro y reencuentro consigo mismo. Las distancias que separan el pasado de nuestro presente dibujan un círculo donde convergen las mismas realidades, a pesar del tiempo y de los espejismos del desarrollo y la modernidad.

En un intento por conciliar la recia ortodoxia del pasado con el presente, preguntaríamos por ejemplo: ¿cuáles serían las distancias que separan a un emperador azteca de un presidente de la República en cuanto a autoridad, tradición y mito? Y en respuesta; con un dejo de ironía, sarcasmo y nostalgia incluso, responderíamos lacónicamente; ninguna... y en una reflexión más honda insistiríamos: ninguna.

Hasta hace muy poco un presidente de la República en nuestro país parecía un personaje sin tacha, casi indefectible. Como la cúspide de una compleja pirámide social, jefe natural y líder máximo del partido en el poder y de todo el sistema político nacional. Justo de ahí se desprendía todo: era el rostro más visto y conocido en México, la voz más es escuchada, el hombre más influyente del país y sin lugar a dudas el personaje más mitificado o vilipendiado del pueblo.

En México podían confundirse muchas voces de hombres públicos excepto una: la del Primer Mandatario de la Nación. Su semblante aparecía repetidamente en medios de comunicación masivos, oficinas burocráticas modestas, medias y ejecutivas, hasta cuadros gigantescos en reuniones oficiales de partido. De hecho, el retrato presidencial atrás de un escritorio resultaba imprescindible para muchos funcionarios que desean demostrar lealtad, respetuosidad por las instituciones y políticas oficiales de gobierno y hasta un servilismo que a menudo se confundía con disciplina.

En México, contrariar al presidente de la República era casi un sacrilegio imperdonable. Sus facultades de decisiones constitucionales, legales, convencionales y tradicionales, eran -y en muchos sentidos siguen siendo- arrolladoras. También tienen un notable predominio sobre los dos poderes restantes, pues los hombres representativos de los poderes de la Unión no pueden contrariar al hombre que ahí los colocó. . 
Así, a pesar de los acontecimientos recientes, el sistema el sistema político mexicano gira alrededor de un hombre -también de carne y hueso-, quien es investido con el honorable nombre de Presidente de la República y, con ello, se convierte durante seis años en Príncipe y Monarca a la vez. En nuestros días, sin lugar a dudas, el Presidente es la pieza clave del sistema político y tiene un enorme predominio sobre los otros elementos políticos que configuran el propio sistema. (Carpizo, 1985: 23-24)

Generalmente el Presidente de la República -tomando una idea de Arnaldo de Córdoba- es el heredero del caudillo revolucionario, pero también es el director de la Administración Pública, responsable de la política exterior, estabilizador de la economía, Jefe del Ejército, líder del partido en el poder, negociador y representante de México, conciliador en la República, etc. Es, en síntesis, la clara y rigurosa personificación del poder nacional. Pero las cosas - como todo en la vida- no surgen por generación espontánea, porque hasta ser dueño de todo tiene su explicación; aclaremos:

Con la Revolución Mexicana se debilitó el cacicazgo, propietario de la nación ancestralmente, para ser relevados por las altas jerarquías políticas. La fundación PNR, en 1929, crea una fabulosa organización de poder alrededor del General Plutarco Elías Calles, éste último, brazo del poder y fundador del presidencialismo de nuestros días. Un personaje extraordinariamente excepcional por su imagen introvertida, seria, inflexible y dictatorial.

Casi de inmediato la fuerza del PRI descansó en las manos del Presidente de la República en turno, y se acentuó a poco tiempo el debilitamiento del poder legislativo, por ser correligionarios del partido en el poder. Visto así, su sometimiento se antoja casi natural.

Otro elemento es la institucionalización de las masas campesinas, obreras y militares, a fin de convertirlas en apéndices de gobierno; el control maestro sobre los medios de comunicación a cambio de privilegios y alianzas con el poder; la concentración de recursos económicos en manos de la federación facilita el manejo de una política presidencial del centro, y finalmente agregaríamos: las facultades que la Constitución General de la República y la ley le otorga han hecho del Presidente de la República una inconfundible institución, no ajeno a mitos y tradiciones paganas.

Así, un Emperador Azteca y Presidente de la República son los nudos contradictorios de nuestra historia no superados, las ataduras férreas que desdibujan los límites entre paganismo y civilización, entre lo obsoleto del pasado y la pretendida modernidad del presente. Son también las heridas de nuestra democracia y los regresos inconscientes al pasado cuando nos preparamos para el futuro. 


\section{El fracaso del nuevo liberalismo social}

Desempolvando de las entrañas del México dela segunda mitad del siglo XIX, el gobierno de Carlos Salinas de Gortari propuso el llamado liberalismo social. En primera instancia, en su sentido más puro y de acuerdo con una apreciación histórica de conjunto que arranca desde las utopías de Ramírez, hasta las reflexiones del Maestro Jesús Reyes Heroles, debiera ser un proyecto político enraizado en la libertad, cuyas fronteras en los ámbitos socio-político y económico reflejan la responsabilidad social y con un especial celo por los intereses nacionales.

Esta idea fue postulada en el sexenio de Salinas como parte no sólo de los cambios en la manera como el Estado debe hacer las cosas en el marco de la reforma del Estado, sino que también se reconoció como parte de la ideología del parido político que lo llevó al poder.

Pero, esto no ha que perderlo de vista, cuando la Historia es utilizada para justificar actos de poder, corre el riesgo de ser una historia condenada a morir.

Más allá de la polémica de si fue correcto o no que el Presidente de la República, en un evento partidista (Aniversario del PRI), manifestará la supuesta ideología que históricamente nos identifica como mexicanos, debemos abocamos al análisis de la Reforma de la Revolución mexicana y el liberalismo social y su estrecho vínculo que tienen con esta necesidad conocida como "reforma del Estado mexicano".

Por primera vez la idea de la "reforma de la Revolución mexicana" fue planteada por el presidente Salinas en su discurso en ocasión del LXXV Aniversario de la Promulgación de la Constitución de 1917. El día 5 de febrero de 1992 se llevó a cabo de dicho evento cívico y fue realizada en el Teatro de la República en la ciudad de Querétaro.

El contenido vertebral del discurso presidencial descansa sobre el argumento de que la Revolución ha sido cambiada permanentemente para la fortuna de los mexicanos; porque se trata de garantizar su naturaleza.

Y el entonces Presidente de la República adujo:

Hoy conmemoramos nuestra Constitución transformando democráticamente nuestra Revolución. En el cambio mantenemos nuestro compromiso con la soberanía y los principios liberales de legalidad libertad, garantías individuales, federalismo, democracia y división de poderes; también en el sentido social y nacionalista que la Revolución nos heredó al establecer en el texto Constitucional la conducción económica de la nación por el Estado, reglas a la economía del mercado el ejercicio democrático del poder y el firme compromiso con la justicia social. 
La propuesta en apariencia resultaba sencilla: se reforma constantemente la Revolución. La pregunta es ¿quién inició, mantuvo y consolidó la Revolución?

La respuesta, según lo que nos ha enseñado la historia de nuestro país, es que gracias al pueblo de México se logró la Revolución. A tal grado es cierta dicha aseveración que, en el artículo 39 de nuestra Carta Magna, se establece el principio de la soberanía popular. El pueblo tiene en todo momento "el inalienable derecho de alterar o modificar la forma de su gobierno a través de los canales de participación previstos en la Constitución General."

¿Cómo es posible que el Presidente afirmara categóricamente que se reformaba la Revolución constantemente. ¿Qué acaso propuso al Congreso de la Unión el perfil ideológico en el que supuestamente participábamos? ¿En alguna ocasión se le preguntó al pueblo o éste manifestó que la Revolución debería estar transformándose?

Creemos que si la Revolución fue una lucha sangrienta del pueblo, corresponde al pueblo y únicamente a él decidir sobre la continuidad o no de la misma. Así, el producto fundamental de la Revolución fueron sus instituciones y no así la propia Revolución. Las instituciones originadas por el movimiento iniciado en 1910 son las que son transformables, y si se quiere su modificación, es necesario que se siga el mecanismo de reformas que la Constitución Política de nuestro país establece.

En una parte de su discurso el Presidente reconoció lo dicho:

(...) modificamos los instrumentos, los medios y las prácticas institucionales pues con el tiempo y ante nuevas circunstancias, 10 que ayer funcionó hoy ya no responde al mundo en el que vivimos.

La importancia de la Revolución mexicana, Y su conversión en mito fundacional, es innegable.

(...) no es extraño que el problema de la historia que hoy hacemos sea por antonomasia, el de la Revolución mexicana: es nuestro referente, pensamos a partir de ella, nos movemos por ella o con ella, en ella y por ella actuamos, sobre ella indagamos el pasado incluso el más remoto, en ella fincamos nuestro desarrollo futuro, parecido o diferente a ella; por ella sornas lo que sornas: ella ha acabado identificándonos como un pueblo y una nación. (Cordova, 1990: 133)

Sin embargo, algunos estudiosos se oponen a la idea de la reforma de la Revolución. Ellos sostienen que la Revolución ya pasó a mejor vida. (Meyer, 1992: 7-12 y Blanco, 1992: 8) 
Otros, en posición mas ecléctica, -que consideramos es la más conveniente- proponen con su crítica una revisión de la ideología de la Revolución mexicana para determinar si realmente prevalece o no. ${ }^{1}$

Nuestro punto de vista ya fue abundado: si bien es cierto no podemos hablar de "reforma de la Revolución mexicana" tampoco lo es que podemos soslayar la importancia que, en nuestra vida social y política, tiene el movimiento social de 1910.

La Revolución mexicana fue producto de varios anhelos, entre los cuales se destaca, como rigurosa síntesis histórica, la búsqueda de la mejor forma de vida de todos los mexicanos. Mientras se siga en la búsqueda de valores como la justicia social, la democracia, las instituciones producto del espíritu de la Revolución -y conste que estamos hablando de instituciones peffileadas por el espíritu del pueblo- ésta se mantendrá perennemente.

Otro de los conceptos que se ha mencionado como parte del factor ideológico de la refoffila de Estado mexicano es el liberalismo social.

El término "liberalismo social" fue empleado con anterioridad por el político y estudioso mexicano Jesús Reyes Heroles, quien dedicó al tema un amplio capítulo en el tercer tomo de su obra El Liberalismo Mexicano. ${ }^{2}$

Aunque es preciso aclarar que fue mucho antes, en Inglaterra, cuando se habló de un concepto de aparente hibridez ideológica. John Stuart MilI habló de la necesidad de socializar el liberalismo de Adam Smith.

En fecha reciente el gran politólogo y filósofo italiano Norberto Bobbio ha sostenido sobre liberalismo -lo que él ha denominado socialismo liberal o liberal socialismo- que hasta el momento "ha quedado o como ideal seductor en teoría como difícilmente traducible en instituciones, o como en fórmulas, pero no la única, que sirven para definir el régimen en el que la

1 Sergio Aguayo Quezada, escribe su comentario: La Revolución Mexicana merece una despedida formal. Cuando sugiero una despedida no estoy pensando en una de esas exaltaciones de jilgueros gritones y aplaudido res de reflejos condicionado. Sugiero la conveniencia de que nos metamos a revisar lo que realmente fue, porque parecería haber una gran prisa por entrar al futuro e ignorar el pasado. La evaluación tiene que abordar, antes que nada, el difícil y recurrente tema de si ha muerto la revolución. Algunos partidarios del nuevo origen aseguran que el viejo modelo sólo se agotó y que lo hicieron fue buscar nuevas alternativas, pero dentro del espíritu revolucionario. Hay algo de cierto en la permanencia de la revolución porque el estilo autoritario se mantiene..."; en "Adiós revolución”, en el periódico La Jornada, México 17 de agosto de 1992, p. 8.

2 Reyes Heroles, Jesús, "El liberalismo mexicano", T. III, pp. 539-674. Si se desea profundizar en el tema del liberalismo social mexicano, cfr. LABRA M., Armando, "Reflexiones sobre el liberalismo social mexicano ", en el periódico La Jornada, México, Porrúa, 1993. pp. 353-520. 
tutela del aparato estatal se amplió de los derechos de la libertad a los derechos sociales." (Bobbio, 1991: 96)

El presidente Salinas retornando la idea de un liberalismo menos egoísta y aprovechando el LXIII Aniversario del Partido Revolucionario Institucional, el día 4 de marzo de 1992, propuso lo que él llamó los "10 principios Básicos del liberalismo social”.

En él, además de que dedica parte de su prefacio a la refoffil la de la revolución mexicana, refiere la otra parte a exponer la "originalidad" de este tipo de liberalismo que lo contrapone al llamado "neo liberalismo".

Del texto del discurso, consideramos que es menester, para el efecto de este trabajo, transcribir íntegramente el punto colocado en tercer lugar:

Tercero: La justicia social

Para el neoliberalismo el ámbito de la sociedad es solamente el de la participación individual, aislada, que dentro de las reglas del individualismo posesivo no tiene por qué incorporar los intereses de los demás en sus decisiones.

Para los neoliberales de justicia se resuelve sola. El crecimiento de la economía derramará en algún tiempo, en el futuro, beneficios que otros pueden aprovechar. Los nuevos reaccionarios, por su parte, quisieran ver al Estado grande y paternalista, aun que se financie con la inflación y excesos.

La justicia social para ellos es decidir qué dar, a quiénes, a través de más burocracia desde el centralismo.

Para nosotros, en el liberalismo social la justicia es un objetivo para el que hay que trabajar deliberadamente. Es un compromiso explícito que tiene que promoverse, al mismo tiempo que se auspicien el crecimiento y la estabilidad. Este es el objetivo de Solidaridad y de la Revolución. La justicia que perseguimos rechaza el paternalismo, que cancela las decisiones de las personas y de las comunidades; también rechaza el populismo que promete cumplir lo que no puede o que luego cobra en deuda, inflación y más miseria.

Solidaridad: expresión actual de nuestro liberalismo social, cumple en los hechos sin romper la disciplina fiscal, respeta efectivamente la dignidad de los mexicanos, porque ellos deciden y participan, lo hacen directamente y sin burocratismos. Nuestro compromiso es la justicia social en los hechos cotidianos.

Sobre este punto en particular también se han instaurado críticas.

A partir del examen ideológico, las réplicas que más se han escuchado son las relativas a la identidad que guardan las acciones del Partido Revolucionario Institucional con el Gobierno; la incongruencia del mensaje presidencial con la realidad, toda vez que, por una parte, se enaltece la labor gubernamental sobre el combate a las desigualdades, $y$, por otra, se observan 
las llagas ocasionadas por la miseria en millones de mexicanos. (Gutiérrez, 1992: I-IV)

Otros autores, como por ejemplo Enrique Krauze y Arnaldo Córdova, han apuntado que el proyecto de liberalismo social es contradictorio.

Aunque el historiador Krauze ha catalogado el discurso presidencial en tomo al liberalismo social de " contradictorio, incompleto y poco claro en el ámbito político" y ha propuesto como solución un liberalismo sin adjetivos, además de pasar por alto los motivos por los .cuales considera deficiente el mencionado discurso, olvida por completo el análisis sobre la inequitativa distribución de la riqueza en México. (El Universal, 3/4/1992:3)

En cambio, el politólogo Arnaldo Córdoba fundamenta su opinión en razones que creemos producen convicción.

Hay que ver lo que significa plantear como valor fundamental la felicidad de la gente, de la comunidad. Hay una contradicción allí. El liberalismo no se define por ningún valor que tenga que ver con la sociedad. La sociedad es el objeto, en el cual la persona hace su acción. El individuo hace la sociedad un objeto para la satisfacción de sus fines.

Hay una contradicción en los términos y en la práctica: reivindicar a la persona, pero, al mismo tiempo, reivindicar a la masa. Es que la persona y la masa están continuamente chocando. No son entidades que puedan combinar pacíficamente. Teóricamente es una contradicción en los términos.

Se plantea simplemente como una definición, a la falta de otras... (1992: 13)

Más allá del debate ideológico, la realidad política mexicana demostró una vez más que de nada sirven los programas de gobierno si no vienen acompañados de una auténtica voluntad política para atender las justas necesidades. Lamentablemente PRONASOL se convirtió en un signo propagandístico, no en pocas veces electoral, que buscó legitimar al poder y que no fue herramienta totalmente eficaz para combatir las dolorosas desigualdades que injustamente prevalecen en el pueblo mexicano.

\section{Referencias bibliográficas}

Blanco, José, 1992: “Un adiós a la revolución mexicana “, en La Jornada, 11 de marzo de 1992, p. 8, México.

Bobbio, Norberto, 1991: Liberalismo y Democracia, México: Fondo de Cultura Económica.

Carpizo, Jorge; 1985: El Presidencialismo Mexicano, México: UNAM. Consejo Consultivo del Programa Nacional de Solidaridad, 1990: El combate a la Pobreza (), México: Edit. El Nacional. 
Cordova, Arnaldo, 1990: “ La historia, maestra de la política “, en Historia ¿para qué?, México: Siglo XXI Editores.

Cordova, Arnaldo, 1992: "Liberalismo social, invento de Reyes Heroles, en una contradicción en sí mismo”, (entrevista), en Proceso No. 801, 9 de Marzo de 1992, p. 13, México.

El Universal, México, Primera Sección, 3 de abril de 1992, p. 3.

Gutiérrez Espindola, José Luis, 1992: "Las réplicas al liberalismo social” en Cuadernos de NEXOS No. 46, abril de 1992, pp. I, II Y IV, México.

Meyer, Lorenzo, 1992: La Segunda Muerte de la Revolución Mexicana, México: Cal y Arena. 